\title{
An assessment of indoor air concentrations and health risks of volatile organic compounds in three primary schools
}

\author{
Sait C. Sofuoglu ${ }^{\mathrm{a}, *}$, Guler Aslan ${ }^{\mathrm{b}, 1}$, Fikret Inal $^{\mathrm{b}}$, Aysun Sofuoglu $^{\mathrm{a}}$ \\ a Izmir Institute of Technology, Department of Chemical Engineering and Environmental Research Center, Gülbahçe, Urla 35430 İzmir, Turkey \\ b Izmir Institute of Technology, Department of Chemical Engineering, Gülbahçe, Urla 35430 İzmir, Turkey
}

\section{A R T I C L E I N F O}

\section{Article history:}

Received 21 May 2010

Received in revised form 4 August 2010

Accepted 18 August 2010

\section{Keywords:}

Indoor air

Formaldehyde

Volatile organic compounds

School

Health risk

İzmir

\begin{abstract}
A B S T R A C T
Concentrations of volatile organic compounds (VOCs), including formaldehyde, in classrooms, kindergartens, and outdoor playgrounds of three primary schools were measured in spring, winter, and fall terms in İzmir, Turkey. A health-risk assessment was conducted for odor detection, sensory irritation, chronic toxic effects, and cancer. Active sampling was applied for VOCs and formaldehyde on Tenax TA and DNPH tubes, respectively. VOCs were analyzed in a thermal desorption-GC-MS system. Formaldehyde analysis was performed using an HPLC instrument. Benzene, toluene, and formaldehyde were the most abundant compounds with 95th percentile indoor air concentrations of 29,87 , and $106 \mu \mathrm{g} / \mathrm{m}^{3}$, respectively. Naphthalene and xylenes followed them with an order of magnitude lower concentrations. Two isomers of dichlorobenzene $(1,3$ and 1,4$)$ were the other notable compounds. The concentrations were utilized to classify the indoor air pollutants with respect to potential health effects. In addition, carcinogenic and chronic toxic risks were estimated using Monte-Carlo simulation. Formaldehyde appears to be the most concerning pollutant with high chronic toxic and carcinogenic risk levels according to the health assessment followed by naphthalene, benzene, and toluene due to their chronic effects.
\end{abstract}

(c) 2010 Elsevier GmbH. All rights reserved.

\section{Introduction}

Primary schools accommodate children aged 7-14 for about 5-8 h daily, which make them the second most time-spent indoor environment after homes. This implies the importance of the schools in terms of the time component of exposure. The other component, the contaminant concentrations, is also important because volatile organic compounds (VOCs) are ubiquitous in the environment since there are many sources (e.g., traffic and industrial emissions as outdoor sources, building and furnishing materials, arts and crafts materials, cleaning agents, and personal care products as indoor sources) (Sexton et al., 2007; Shendell et al., 2004). There are also other factors that influence indoor air quality: schools are commonly associated with high population density, poor ventilation, lack of maintenance, and unsatisfactory cleaning (Daisey et al., 2003; Smedje et al., 1997). School children are more sensitive to environmental pollutants than adults, because of their higher breathing rate relative to their body size, and continuing growth (Faustman et al., 2000), which translate into higher healthrisk levels. Moreover, according to critical reviews, there are studies

\footnotetext{
* Corresponding author. Tel.: +90 232750 6648; fax: +90 2327506645 .

E-mail addresses: saitcemil@iit.edu, cemilsofuoglu@iyte.edu.tr (S.C. Sofuoglu). 1 Abant Izzet Baysal University, Department of Environmental Engineering, Gölköy 14280 Bolu, Turkey.
}

relating poor indoor environmental quality in schools to the performance of students (Mendell and Heath, 2005), and poor ventilation to health symptoms (Daisey et al., 2003). Some of the VOCs are associated with variety of serious health effects (Sax et al., 2006; Shendell et al., 2004) and symptoms such as asthma and allergic reactions.

Allergic symptoms and diseases are common among children. It has been estimated that there were 6.8 million children with asthma (ALA, 2007) in the US, which was the principal cause of school absenteeism accounting for $20 \%$ of lost school days in elementary and high schools (Bayer et al., 2000). Demir et al. (2004) reported the prevalence of asthma in 1992, 1997, and 2002 at a primary school in Ankara, Turkey, as 8.3\%, 9.8\%, and 6.4\%, respectively. In Edirne, Turkey, prevalence of asthma among primary school children was estimated as $5.6 \%$, however $34 \%$ of the children experienced an allergy problem at some time in their life (Selcuk et al., 1997). Ones et al. (2005) reported that the prevalence of childhood asthma in Turkey varies between $3.8 \%$ and $12.9 \%$. Meanwhile, a recent large-scale survey (more than 25,000 children in 14 cities in Turkey) showed that median prevalence values for asthma, wheezing, allergic rhinitis, and eczema were estimated as $13.4 \%, 12.6 \%$, $17.3 \%$, and $4.6 \%$, respectively (Kurt et al., 2007).

Formaldehyde, the leading aldehyde in terms of both detection frequency and concentration levels, is considered separately since aldehydes require different sampling and analysis procedures than other VOCs. Norback et al. (1990) studied VOC and 
formaldehyde concentrations in six classrooms in Sweden. It was reported that, the concentration of formaldehyde was below the detection limit $\left(<10 \mu \mathrm{g} / \mathrm{m}^{3}\right)$ and the mean indoor Total VOC (TVOC) concentrations ranged from 70 to $180 \mu \mathrm{g} / \mathrm{m}^{3}$. VOCs were investigated in randomly selected 38 public schools ( 96 classrooms) by Smedje et al. (1997). Formaldehyde was below the detection limit of $5 \mu \mathrm{g} / \mathrm{m}^{3}$, the mean sum of 14 identified VOCs was $35 \mu \mathrm{g} / \mathrm{m}^{3}$, and the highest concentrations were of limonene, $n$-decane, toluene, and xylene. Lee et al. (2002) measured VOCs in 10 schools with airconditioned classrooms located in urban, industrial, and residential areas in Hong Kong. Average indoor formaldehyde concentrations did not exceed the standard $\left(100 \mu \mathrm{g} / \mathrm{m}^{3}\right)$. The most abundant and frequently found VOCs were benzene, toluene, ethybenzene, $\mathrm{p} / \mathrm{m}$ xylene, and $o$-xylene with the mean values of $3.13,17.7,4.20$, 3.30 , and $1.66 \mu \mathrm{g} / \mathrm{m}^{3}$, respectively. According to a review (Daisey et al., 2003), the average TVOC concentrations ranged from 100 to $1600 \mu \mathrm{g} / \mathrm{m}^{3}$ in different European and US schools while the mean formaldehyde concentrations in the schools ranged from 10 to $430 \mu \mathrm{g} / \mathrm{m}^{3}$. The highest median VOC concentrations measured in Minnesota, USA, schools were reported as 4.6, 2.9, and $2.3 \mu \mathrm{g} / \mathrm{m}^{3}$ for $d$-limonene, toluene, and $m, p$-xylene, respectively (Adgate et al., 2004), where winter term concentrations were higher than those measured in spring term. A year long sampling was performed in three primary schools in Western Australia (Zhang et al., 2006). Ten compounds were identified (benzene, toluene, chlorobenzene, $m, p$-xylene, $o$-xylene, ethylbenzene, styrene, 1,2-dichlorobenzene, 1,3-dichlorobenzene, and 1,4-dichlorobenzene) at low concentrations (TVOC $<100 \mu \mathrm{g} / \mathrm{m}^{3}$ ) of which the highest was measured in a visual art classroom. Godwin and Batterman (2007) conducted a study in 64 classrooms in a suburban school district not under the effect of ambient pollution sources in Michigan, USA. The most prevalent VOCs were benzene, ethylbenezene, toluene, xylene, and limonene but the concentrations were low with the mean TVOC level of $58 \mu \mathrm{g} / \mathrm{m}^{3}$. In general, the literature reported higher indoor, winter, and kindergarten VOC concentrations compared to outdoor, summer, and classrooms, respectively.

Although VOC concentration levels for schools in Turkey (Kocaeli) were reported before (Pekey and Arslanbaș, 2008), the focus was on the homes and offices. This is the first study that focuses on the school indoor air in Turkey, and assesses associated health risks. The aims of the study were to (1) measure VOC concentrations, including formaldehyde, in primary school classrooms, kindergartens, and outdoor playgrounds in fall, winter, and spring terms at three public schools, two located in the urban and one located in suburban İzmir, Turkey, and (2) conduct an assessment to estimate associated human health risks, and to classify the VOCs accordingly.

\section{Materials and methods}

\section{Site description and sampling}

İzmir, the third most populated province in Turkey with a population of approximately four million, is located on the Aegean Sea shore, where the majority of the population $(\sim 70 \%)$ resides in the metropolitan area. Three public schools, hereinafter School-1, School-2, and School-3, were selected based on their accessibility, availability, and willingness to participate, as well as their different geographic characteristics and building structure properties. Schools- 1 and -2 are in the urban area whereas School-3 is in a suburban area, approximately $50 \mathrm{~km}$ away from the downtown. The general descriptions and some properties of the sampled buildings and classrooms are presented in the Supporting Material.

As the sampling strategy, there were three sampling sites in each school: a classroom, the kindergarten, and the playground (out- door). Sampling was conducted weekdays between 11 AM and 4 $\mathrm{PM}$, in winter, spring, and fall. Classroom was the main site. Nine samples were collected in winter and spring, and six samples were collected in fall from the classrooms. Three samples were collected from each of the other two sites (i.e., kindergarten and playground) in winter and spring. In the last sampling campaign (fall), the number of samples had to be reduced to two for both kindergartens and outdoors. In general, test space properties were similar among the three schools, nonetheless there were some differences (e.g., in room area, cooling, and air freshener use).

EPA TO-17 (USEPA, 1999a) and TO-11 (USEPA, 1999b) methods were followed to determine the concentrations of VOCs and formaldehyde, respectively. Tenax TA stainless steel thermal desorption tubes filled with $100 \mathrm{mg}$ sorbent (SKC 226-340) was used for VOCs. Sorbent sample tube for formaldehyde (SKC 226-120) is a three-section tube containing 300 and $150 \mathrm{mg}$ of DNPH-coated silica gel in sample and backup sections, respectively, and a $1500 \mathrm{mg}$ section of potassium iodide that acts as an ozone scrubber to eliminate atmospheric ozone interference. The average flow rate in this study was set at $1300 \mathrm{ml} / \mathrm{min}$ for DNPH silica gel tubes and $66.7 \mathrm{ml} / \mathrm{min}$ for Tenax TA tubes. Based on these flow rates in a 60min sampling period, approximately 80 and $41( \pm 10 \%)$ of air were collected in DNPH and Tenax TA tubes, respectively.

Tenax TA tubes were conditioned for at least $30 \mathrm{~min}$ at $350^{\circ} \mathrm{C}$ while passing at least $50 \mathrm{ml} / \mathrm{min}$ of pure helium as carrier gas before the first use. Purge time was $1 \mathrm{~min}$ and desorb-time was $3 \mathrm{~min}$ at $300^{\circ} \mathrm{C}$. DNPH silica gel tubes were for one-time-use only, therefore did not require any preconditioning. After conditioning, Tenax TA tubes were capped with Swagelok ${ }^{\circledR}$ fittings using PTFE ferrules. DNPH silica gel and conditioned Tenax TA tubes were wrapped with aluminum foil and placed in a storage container to protect from the light and maintain at $4{ }^{\circ} \mathrm{C}$ during the transportation. The tubes were stored in the refrigerator until the analysis. It is recommended that the refrigeration period prior to analysis should not exceed two weeks (USEPA, 1999a). In this study, the Tenax TA tubes were analyzed in two days. The extraction of the DNPH silica gel tubes were performed in two weeks, and analyzed in two weeks after the extraction.

\section{Analytical methods}

VOCS

Tenax TA sorbent sample tubes were analyzed by an automated short-path thermal desorption/cryofocusing system (Unity Markes International Limited) that sits on injector/septum area of a gas chromatography (GC) (Agilent 6890N) mass spectrometry (MS) (Agilent 5973Nms) system. Operating conditions for the thermal desorption are presented in the Supporting Material.

\section{Formaldehyde}

In the extraction, $6 \mathrm{ml}$ of acetonitrile (Merck 1.00030, 99.9\%) was used as the solvent. Stainless steel gas tight syringes (Agilent Gas Tight Luer Lock Valve 5183-4552 and 4451) were used to flow acetonitrile through the cartridges. Three $\mathrm{ml}$ of sample elution from the cartridge was collected into $4 \mathrm{ml}$ vials (National Scientific, Screw Caps with PTFE Septa, C4015-1). Before eluting derivatives, all glassware were cleaned by rinsing with acetonitrile, and then heated in a $60^{\circ} \mathrm{C}$ vacuum oven for at least $30 \mathrm{~min}$. The vial was kept in the refrigerator $\left(4^{\circ} \mathrm{C}\right)$ until HPLC analysis. Operating conditions of the HPLC system (Agilent 1100) are given in the Supporting Material.

\section{Quality assurance/quality control}

The calibration standard solution contained 60 volatile organic compounds (LGC Promochem U-DWM-580). However, the analytical method could be satisfactorily optimized for 51 of them. Five 
levels of calibration standards $(0.2,2,10,20$, and $40 \mu \mathrm{g} / \mathrm{ml})$ were used to prepare the calibration curves. For all the compounds the linear fit was satisfactory $\left(R^{2}>0.99\right)$. DNPH-formaldehyde derivative liquid standards were purchased from a manufacturer (LGC Promochem CERERF-004S). Calibration standards were prepared in acetonitrile at seven levels $(0.05,0.1,0.2,0.5,1,2$, and $5 \mu \mathrm{g} / \mathrm{ml})$. Each calibration standard was analyzed three-times and area response was tabulated against the mass concentration injected. The calibration curve was a satisfactory linear fit $\left(R^{2}>0.99\right)$. Field blanks were collected and analyzed to assess possible contamination through the sample collection and analysis process, which corresponded to $10 \%$ of the total number of samples. Twenty-one of the 51 VOCs were detected in the field blank samples, the mean field blank level was $<8 \%$ of the mean sample level except for formaldehyde (10.75\%). Limit of Detection (LOD) was calculated for each analyte using five field blanks, and Method Detection Limits (MDL) were calculated from the seven replicate analysis of a low concentration sample. Breakthrough volume analysis was performed to ensure that the sampling volume was adequate for the sorbent tube using a second identical sampling tube placed in series with a primary (front) tube $(n=3)$. The target amounts in the backup tubes were $<5 \%$ of the observed analytes in the front tubes. Duplicate precision was estimated as the absolute value of the relative difference between two identical parallel samples $(n=3)$. The agreement between the duplicates was within $\pm 25 \%$. The calculated LOD and MDL values, and results of the duplicate precision and breakthrough volume analyses are presented in the Supporting Material. The performances of the sampling pumps were checked continually. The pumps were calibrated before each sampling using a flow controller (Defender 510, Bios International Corp.). The flow rates were recorded at the beginning and at the end of the sampling to make sure that the loss due to pressure drop was within the predefined limit of $10 \%$.

\section{Health-risk assessment}

An assessment was conducted for odor detection, sensory irritation, and chronic toxic effects following the methodology presented by Hodgson and Levin (2003) for classification of VOCs. They defined Hazard Quotients (HQs) based on their selected best estimates of guidance levels for the above mentioned health effects. Values of HQs (Odor Quotient, OQ Sensory Irritation Quotient, SIQ and Chronic Toxicity Quotient, CTQ) were found by dividing the maximum or 95th percentile concentrations by the best estimate guidance levels. The best estimates were drawn from the literature for OQ; from adjusted Nasal Pungency Thresholds (NPTs), adjusted mouse $\mathrm{RD}_{50}$ values (concentration that cause $50 \%$ decrease in breathing frequency), acute Reference Exposure Levels (RELs), and adjusted Threshold Limit Values (TLVs) for SIQ; and from Minimal Risk Levels (MRLs), RELs, RfCs, and TLVs for CTQ.

An additional health-risk assessment was carried out using Monte-Carlo simulation for the pollutants with published risk factors by US Environmental Protection Agency (EPA), Integrated Risk Information System (IRIS).

The following equation was used for calculation of daily inhalation exposure for each compound:

$\mathrm{CDI}_{i}=\frac{C_{i} \times \mathrm{IR}_{i} \times \mathrm{ED}_{i}}{\mathrm{BW}}$

where $C$ is the contaminant concentration $\left(\mu \mathrm{g} / \mathrm{m}^{3}\right)$, IR is inhalation rate $\left(\mathrm{m}^{3} / \mathrm{h}\right)$, ED is exposure duration $(\mathrm{h}), \mathrm{BW}$ is the body weight $(\mathrm{kg})$, and, CDI is the chronic daily intake for a school day ( $\mu \mathrm{g} / \mathrm{kg} /$ day) for three microenvironments $(i)$ : kindergarten, classroom, and outdoor playground. Data for the determination of IR and BW probability distributions were obtained from the literature. BW distribution was constructed using the updated (Neyzi et al., 2008) reference data (Neyzi et al., 1973) for Turkish children. IR distributions in the three microenvironments were constructed using the recommended mean values for five levels of activity for the American children (USEPA, 1997a). The daily time spent in the three microenvironments was taken as $4 \mathrm{~h}$ for classrooms and kindergartens (six 40-min classes) and $1 \mathrm{~h}$ for outdoor playground (one 20-min and four 10-min breaks). Cancer risk associated with inhalation exposure was calculated by

$R=\sum_{i=1}^{I} \frac{\mathrm{CDI}_{i} \times \mathrm{SF}}{\mathrm{AT}}$

where $R$ is the probability of excess cancer risk, SF is the slope factor of the chemical $(\mu \mathrm{g} / \mathrm{kg} / \mathrm{day})^{-1}$, and AT is averaging time which is lifetime for cancer risk assessment, $I=3$ for the three microenvironments. ED is taken as 1 year for kindergarten and 8 years for classroom, and AT is assumed as standard lifetime of 70 years (25,550 days). A school year is assumed as 150 days for the both, making $E D=150$ days for kindergarten, and 1200 days for primary schools.

The hazard quotient (HQ) levels were calculated using the following equation for chronic toxic effects.

$\mathrm{HQ}=\frac{\mathrm{CDI}}{\mathrm{RfD}}$

where RfD is the reference dose ( $\mu \mathrm{g} / \mathrm{kg} /$ day).SF and RfD values were obtained from the USEPA (IRIS, 2009) by back-calculating from the published unit risk and reference concentration values based on the standard adult inhalation rate and lifetime, $20 \mathrm{~m}^{3} /$ day and 70 years, respectively. Using dose variables in addition to the concentrations to estimate the risks, we intended to better describe the situation rather than just dividing or multiplying by a Reference Concentration (RfC) or Unit Risk. Probability distributions fitted to pollutant concentrations, and constructed for IR and BW are presented in the Supporting Material.

\section{Statistical methods}

Statistical analyses were performed with SPSS (v.10) software. The non-parametric Mann-Whitney $U$ test was used to test whether two independent samples are from the same population (whether medians differ significantly). The Kruskal-Wallis test was applied to compare more than two groups to test the null hypothesis that all groups have identical distribution functions against the alternative hypothesis that at least two of the samples differ only with respect to location (median), if at all. A significance level of 0.05 was used in all statistical testing.

All risk levels were estimated probabilistically using MonteCarlo simulation method using Crystal Ball software (v 4.0e). Monte-Carlo Simulation is a computer-based method of analysis that uses statistical sampling techniques in obtaining a probabilistic approximation to the solution of a mathematical equation or a model (USEPA, 1997b). For each variable in an equation, the possible values are defined with a probability distribution. Probability distributions of VOC concentrations were determined by fitting continuous distributions (beta, exponential, extreme value, gamma, logistic, lognormal, normal, and Weibull) to measured data by the help of goodness-of-fit tests which were chi-square, Kolmogorov-Smirnov, and Anderson-Darling tests. The simulation software was also used in fitting distributions, which provides values of the test statistics, and allows the user to determine the best fitting distribution. These probability distributions and the distributions of IR and BW obtained from the literature (referenced in 'Health-risk assessment' section) were used as the input distributions for exposure model variables. During a single trial, values were randomly selected from the defined probabilities (the range 
and shape of the distribution) for each uncertain variable; and then the output of the models (the two risk equations given in 'Healthrisk assessment' section), which are chronic toxic and carcinogenic risk was calculated. If a simulation is run for 10,000 trials, 10,000 forecasts (or possible outcomes) are created compared to the single outcome obtained in the deterministic approach. Population exposure and risk distributions were estimated using the simulated values $(n=10,000)$.

\section{Results and discussion}

\section{Concentrations}

Indoor and outdoor VOC concentrations, including formaldehyde, were measured at three primary schools in three seasons (winter, spring, and fall) in İzmir, Turkey. The following sections present results and discussions on indoor concentrations measured in the classrooms and the kindergartens, and outdoor concentrations measured on the playgrounds.

\section{Classroom}

Formaldehyde was detected in all of the samples. Excluding formaldehyde, the number of VOCs quantified ranged between 25 (School-2, fall) and 37 (School-3, spring) in at least one sample, while it was 12-19 (average=16) in all the samples. Concentrations measured in classrooms are presented as a season-school matrix (Fig. 1). Benzene, chloroform, 1,3-dichlorobenzene, 1,4-dichlorobenzene, naphthalene, toluene, trichloroethene, and xylenes were the compounds measured at relatively higher concentrations. Toluene and benzene were among the most abundant three compounds with overall mean concentrations of 18.7 and $10.4 \mu \mathrm{g} / \mathrm{m}^{3}$, respectively, which were an order of magnitude higher than the remaining six compounds (the means ranged between $8.9 \mu \mathrm{g} / \mathrm{m}^{3}$ for 1,4-dichlorobenzene and $0.7 \mu \mathrm{g} / \mathrm{m}^{3}$ for trichloroethene and $o$-xylene).

The differences in the mean concentrations measured in the two urban schools were variable among the three sampling campaigns: low in winter and spring $\left(25.7 \mu \mathrm{g} / \mathrm{m}^{3}\right.$ vs. $26.6 \mu \mathrm{g} / \mathrm{m}^{3}$ and $16.5 \mu \mathrm{g} / \mathrm{m}^{3}$ vs. $15.5 \mu \mathrm{g} / \mathrm{m}^{3}$, respectively) but higher in fall $\left(12.4 \mu \mathrm{g} / \mathrm{m}^{3}\right.$ vs. $\left.8.9 \mu \mathrm{g} / \mathrm{m}^{3}\right)$ for toluene, low in spring and fall $\left(8.3 \mu \mathrm{g} / \mathrm{m}^{3}\right.$ vs. $6.3 \mu \mathrm{g} / \mathrm{m}^{3}$ and $5.2 \mu \mathrm{g} / \mathrm{m}^{3}$ vs. $3.5 \mu \mathrm{g} / \mathrm{m}^{3}$, respectively) but higher in winter $\left(16.4 \mu \mathrm{g} / \mathrm{m}^{3}\right.$ vs. $\left.10.6 \mu \mathrm{g} / \mathrm{m}^{3}\right)$ for benzene. Concentrations of these two compounds were higher in the urban schools in fall compared to the suburban school with an average difference of 2.6 folds for toluene, and 4.4 folds for benzene. However, this was not the case in winter and spring, as higher mean concentrations were measured in the suburban school with an average difference of 1.4 folds for toluene, and 2.0 folds for benzene. The
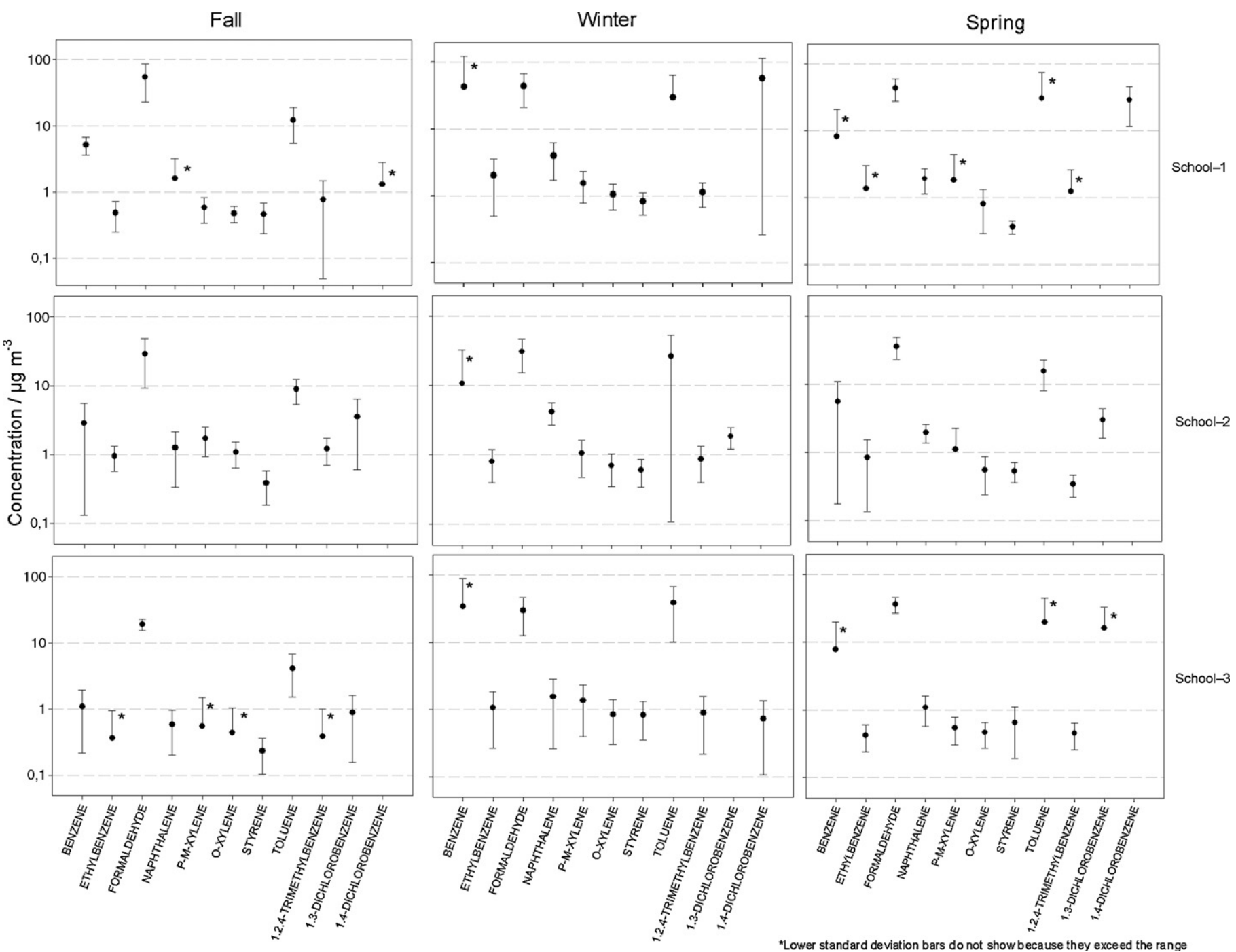

Fig. 1. Season-school matrix for indoor air VOC concentrations measured in the classrooms. 
Table 1

The mean toluene/benzene and toluene/ $\mathrm{TVOC}_{51}$ ratio values, $\mathrm{TVOC}_{51}$ and formaldehyde concentrations.

\begin{tabular}{|c|c|c|c|c|c|c|c|c|c|c|}
\hline \multirow[t]{2}{*}{ School } & \multirow[t]{2}{*}{ Area } & \multicolumn{3}{|c|}{$\begin{array}{l}\text { Toluene/benzene } \\
\text { Toluene/TVOC } 51\end{array}$} & \multicolumn{3}{|c|}{$\operatorname{TVOC}_{51}\left(\mu \mathrm{g} \mathrm{m}^{-3}\right)^{\mathrm{a}}$} & \multicolumn{3}{|c|}{ Formaldehyde $\left(\mu \mathrm{g} \mathrm{m}^{-3}\right)^{\mathrm{a}}$} \\
\hline & & Fall & Winter & Spring & Fall & Winter & Spring & Fall & Winter & Spring \\
\hline 1 & Classroom & $\begin{array}{l}2.4 \\
0.46\end{array}$ & $\begin{array}{l}1.6 \\
0.23\end{array}$ & $\begin{array}{l}2.0 \\
0.25\end{array}$ & $27 \pm 11$ & $111 \pm 64$ & $66 \pm 49$ & $55 \pm 32$ & $49 \pm 20$ & $44 \pm 16$ \\
\hline 2 & Classroom & $\begin{array}{l}3.1 \\
0.34\end{array}$ & $\begin{array}{l}2.5 \\
0.52\end{array}$ & $\begin{array}{l}2.4 \\
0.48\end{array}$ & $26 \pm 8$ & $51 \pm 48$ & $32 \pm 16$ & $29 \pm 20$ & $31 \pm 17$ & $36 \pm 13$ \\
\hline 3 & Classroom & $\begin{array}{l}4.5 \\
0.40\end{array}$ & $\begin{array}{l}1.1 \\
0.43\end{array}$ & $\begin{array}{l}2.2 \\
0.39\end{array}$ & $10 \pm 8$ & $91 \pm 88$ & $51 \pm 43$ & $19 \pm 4$ & $30 \pm 17$ & $37 \pm 10$ \\
\hline 1 & Kindergarten & $\begin{array}{l}1.6 \\
0.46\end{array}$ & - & $\begin{array}{l}21 \\
0.75\end{array}$ & $58 \pm 24$ & - & $130 \pm 30$ & $109 \pm 18$ & - & $67 \pm 25$ \\
\hline 2 & Kindergarten & $\begin{array}{l}1.5 \\
0.44\end{array}$ & $\begin{array}{l}2.4 \\
0.47\end{array}$ & $\begin{array}{l}4.4 \\
0.64\end{array}$ & $43 \pm 16$ & $70 \pm 7$ & $56 \pm 15$ & $92 \pm 17$ & $87 \pm 36$ & $85 \pm 22$ \\
\hline 3 & Kindergarten & $\begin{array}{l}2.4 \\
0.56\end{array}$ & - & $\begin{array}{l}4.1 \\
0.47\end{array}$ & $33 \pm 38$ & - & $45 \pm 24$ & $78 \pm 23$ & - & $76 \pm 20$ \\
\hline 1 & Outdoor Playground & $\begin{array}{l}2.2 \\
0.5\end{array}$ & $\begin{array}{l}1.6 \\
0.5\end{array}$ & $\begin{array}{l}1.8 \\
0.4\end{array}$ & $22 \pm 2$ & $41 \pm 19$ & $24 \pm 20$ & $8.8 \pm 2.1$ & $7.6 \pm 0.4$ & $7.6 \pm 1.3$ \\
\hline 2 & Outdoor Playground & $\begin{array}{l}1.5 \\
0.3\end{array}$ & $\begin{array}{l}0.9 \\
0.4\end{array}$ & $\begin{array}{l}1.3 \\
0.4\end{array}$ & $16 \pm 8$ & $16 \pm 9$ & $13 \pm 8$ & $6.1 \pm 2.9$ & $7.2 \pm 1.6$ & $7.2 \pm 6.5$ \\
\hline 3 & Outdoor Playground & $\begin{array}{l}3.2 \\
0.5\end{array}$ & $\begin{array}{l}1.6 \\
0.5\end{array}$ & $\begin{array}{l}0.7 \\
0.2\end{array}$ & $10 \pm 4$ & $42 \pm 28$ & $25 \pm 2$ & $2.3 \pm 1.5$ & $5.9 \pm 3.4$ & $0.6 \pm 0.03$ \\
\hline
\end{tabular}

${ }^{\mathrm{a}}$ Mean \pm Standard Deviation.

spatial comparison of VOCs helps to elaborate on the strength of the outdoor air as a source. Benzene and toluene concentrations do not show a clear pattern between the urban and the suburban schools, implicating the importance of the indoor sources. Toluene and benzene were used to identify traffic emissions in the literature. Toluene/benzene ratio (T/B) was shown to be a good predictor of distance from urban traffic for which T/B was estimated as 2.0, and reduced to about unity in a rural area (Gelencsér et al., 1997). Actually, T/B ratio values (calculated from the reported mean concentrations) were 2.3 and 1.6 at two sites with heavy traffic in İzmir (Muezzinoglu et al., 2001). The T/B values in this study are shown in Table 1, which point to a noticeable effect of the traffic emissions on the VOC concentrations measured in winter and spring campaigns. In fall, however, benzene concentration in the suburban school classroom was low (at the same order of magnitude with the remaining six compounds, see Fig. 1, resulting in a high $\mathrm{T} / \mathrm{B}$ value).

Although, toluene and benzene constituted the majority of total concentration, TVOC $_{51}$ may be a better means of temporal and spatial comparison because it would be difficult to contemplate a number of individual compounds. The mean TVOC $_{51}$ concentration was the highest in the winter term followed by the spring and fall terms (Table 1). Like toluene and benzene, TVOC $_{51}$ concentrations do not show a clear separation between the urban and the suburban schools, implicating the importance of the indoor sources. One of the important observations in the school buildings was that although indoor walls of all the three schools were painted with water based paints in the summer break, the walls in School-1 were partially painted again with a solvent based paint up to a height of $1.5 \mathrm{~m}$, including the heating system radiators in the winter break, which resulted in a strong odor when the heating system was turned back on. This may be the reason why Schools- 1 and -2 differed significantly. Comparison of the median TVOC $_{51}$ values with Kruskal-Wallis test showed that at least one of the schools in each season had a significant difference $(p<0.02)$. Then, comparison of the seasonal median concentrations showed that the differences were statistically significant between fall and spring $(p=0.01)$, and fall and winter $(p=0.002)$ at School- 1 , and fall and spring $(p=0.007)$, and fall and winter $(p=0.006)$ at School-3. The remaining seasonal differences in medians were not statistically significant.

The TVOC concentrations measured in this study were either at similar or higher than the studies performed in schools in other countries: in Sweden (mean TVOC of $6 \mu \mathrm{g} / \mathrm{m}^{3}$ by Smedje et al.,
1997), in Minnesota, USA (median TVOC of $14 \mu \mathrm{g} / \mathrm{m}^{3}$ by Adgate et al., 2004), in Australia ( $\max$ TVOC of $94 \mu \mathrm{g} / \mathrm{m}^{3}$ by Zhang et al., 2006), and in Michigan, USA (mean TVOC of $58 \mu \mathrm{g} / \mathrm{m}^{3}$ by Godwin and Batterman, 2007), but lower than those measured in South Korea (mean TVOC of $374 \mu \mathrm{g} / \mathrm{m}^{3}$ by Yang et al., 2009). However, one should note that different definitions of TVOC were used, e.g., TVOC $_{10}$ (Zhang et al., 2006) and sum of the both target and non-target peaks normalized to toluene equivalents (Godwin and Batterman, 2007).

Among the VOCs analyzed in this study dichlorobenzene (1,3and 1,4-) and naphthalene were the abundant compounds in addition to benzene, formaldehyde, and toluene. Main indoor sources of 1,4-dichlorobenzene and naphthalene are common: mothballs and bathroom deodorizers (Godwin and Batterman, 2007; Mendell, 2007). Both isomers of dichlorobenzene are also emitted from cleaning agents (Stellman, 1998). In the past, naphthalene was a popular product against pests, and today mothballs are commonly used indoors in Turkey (all the three schools were using mothballs in the washrooms). Naphthalene was also detected in drinking water samples at significant concentrations ( median $=0.03 \mu \mathrm{g} / \mathrm{l}$, 90th percentile $=0.11 \mu \mathrm{g} / \mathrm{l}$ ) that were similar to benzene and toluene, in İzmir (Kavcar et al., 2006). The mean concentrations of 1,4-dichlorobenzene were below detection limit (BDL) in School-2 in all seasons and in School-3 in spring while the mean 1,3-dichlorobenzene and naphthalene levels were at detectable levels except for one instance (1,3dichlorobenzene, spring, School-1). Thus, 1,4-dichlorobenzene had very strong source(s) in one school, while 1,3-dichlorobenzene had weaker consistent source(s). The overall mean and maximum concentrations for 1,3- and 1,4-dichlorobenzene, and naphthalene were 3 and $52 \mu \mathrm{g} / \mathrm{m}^{3}, 9$ and $142 \mu \mathrm{g} / \mathrm{m}^{3}$, and 2 and $8 \mu \mathrm{g} / \mathrm{m}^{3}$, respectively. The 1,3-dichlorobenzene levels were two orders of magnitude higher than those measured in Michigan, USA, schools that were located in suburban area away from major outdoor sources, while the naphthalene levels were similar, and 1,4dichlorobenzene was not detected at all in these schools (Godwin and Batterman, 2007). Dichlorobenzene levels were, however, much lower than domestic concentrations (median $=55 \mu \mathrm{g} / \mathrm{m}^{3}$, maximum $=622 \mu \mathrm{g} / \mathrm{m}^{3}$ ) reported by Rumchev et al. (2004).

One of the most potent and studied compounds in indoor air is formaldehyde as it has strong indoor sources. Fig. 1 shows that formaldehyde was either the highest concentration compound among those measured in this study or was at comparable 
levels with toluene and benzene. The mean and median concentrations were all close and ranged from $19 \mu \mathrm{g} / \mathrm{m}^{3}$ (School-3, fall) to $55 \mu \mathrm{g} / \mathrm{m}^{3}$ (School-1, fall). The most pronounced difference among the three schools in formaldehyde concentrations were observed in fall campaign (the difference between the Schools- 1 and -3 was $\left.36 \mu \mathrm{g} / \mathrm{m}^{3}\right)$, while the gap was not as wide in winter $\left(14 \mu \mathrm{g} / \mathrm{m}^{3}\right)$ and spring $\left(8 \mu \mathrm{g} / \mathrm{m}^{3}\right)$. The common observation for the winter and spring campaigns for formaldehyde was that average levels were similar in spring and winter in Schools- 2 and -3 but not in the fall. School-1 had the highest average concentration in all seasons (see Table 1 ). The mean value of all measured concentrations (overall school mean) in School-1 was $47 \mu \mathrm{g} / \mathrm{m}^{3}$ which was considerably higher than the other two schools $\left(32 \mu \mathrm{g} / \mathrm{m}^{3}\right.$ in Schools-2 and $31 \mu \mathrm{g} / \mathrm{m}^{3}$ in School-3). These spatial variations were different than the variation in $\mathrm{TVOC}_{51}$, except that the highest mean concentrations were measured in School-1. Nevertheless, having similar concentrations in urban and suburban schools, and having different concentrations between two urban schools point to the relative strength of the indoor sources compared to the outdoor sources as formaldehyde is known to have strong indoor sources.

The differences between the highest and the lowest seasonal averages were relatively small for formaldehyde (21\%, $19 \%$, and $48 \%$ for Schools-1, -2 , and -3 , respectively) but higher variations were observed for TVOC $_{51}$ (75\%, 48\%, and $89 \%$ for Schools-1, -2, and -
3 , respectively), which hints at relatively more consistent sources for formaldehyde and more variable sources for VOCs in terms of emission strength. The formaldehyde concentrations measured in this study were in the literature range $\left(10-400 \mu \mathrm{g} / \mathrm{m}^{3}\right.$, Daisey et al., 2003). The concentrations measured in this study were higher than those reported for schools in other countries (Sweden, Norback et al., 1990; Smedje et al., 1997; Hong Kong, Lee et al., 2002; Australia, Zhang et al., 2006), while they were lower than the concentrations measured in homes and offices (Vaizoglu et al., 2003; Khoder, 2006; Mentese and Gullu, 2006; Park and Ikeda, 2006), and were similar to those in libraries (Hanoune et al., 2006; Righi et al., 2002).

\section{Kindergarten}

All the three schools investigated in this study had a kindergarten. Samples were collected from the kindergartens and analyzed for VOCs and formaldehyde. Because the number of samples collected in each campaign was low $(n=3)$, evaluations presented in this section are based on the compounds that were detected in all three samples. The number of compounds that comply with this criterion ranged from 16 (School-3, spring) to 24 (School-2, fall); overall average was 20 compounds. Toluene followed by benzene were the highest concentration compounds in almost all campaigns, which were the only two compounds that reached the two-digit concentration levels (Fig. 2). The other frequently detected high-concentration $\left(\geq 1 \mu \mathrm{g} / \mathrm{m}^{3}\right)$ compounds were
Fall
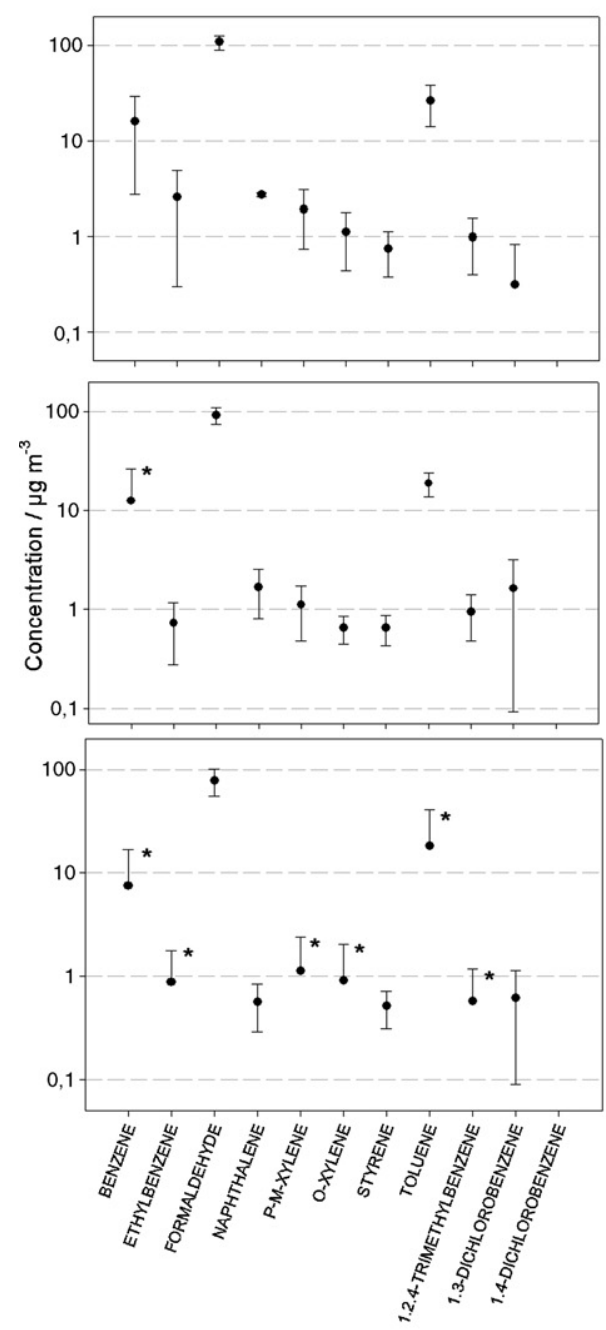

Winter
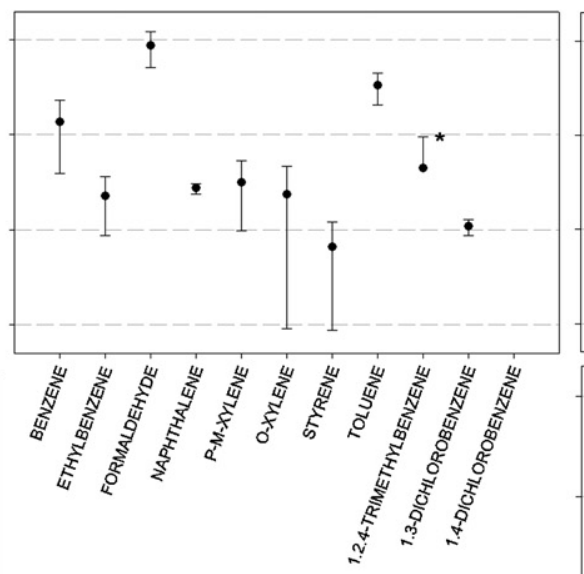

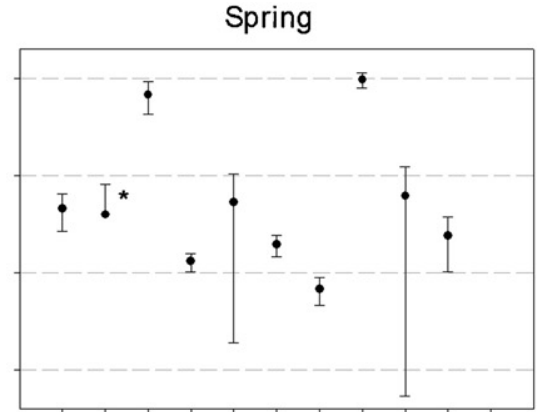

School-1

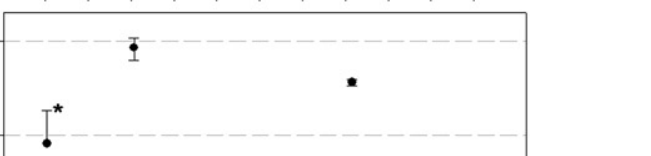

School-2
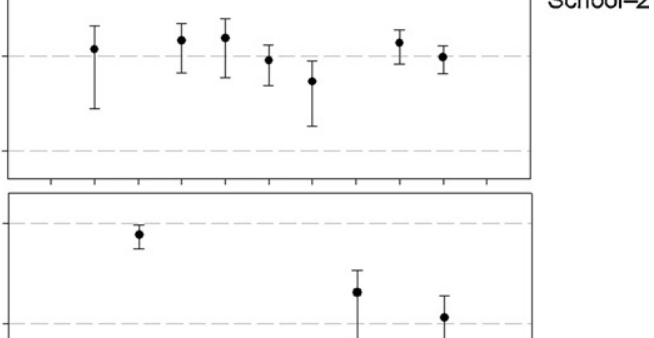

School-3
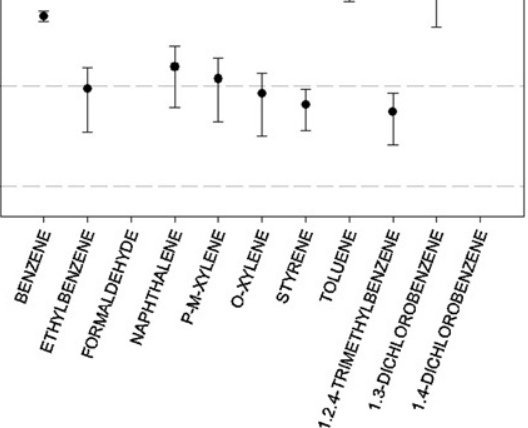

*Lower standard deviation bars do not show because they exceed the range

Fig. 2. Season-school matrix for indoor air VOC concentrations measured in the kindergartens. 
1,3-dichlorobenzene, ethylbenzene, $o$-xylene, $p, m$-xylene, naphthalene, and 1,2,4-trimethylbenzene. There were lost samples in the winter campaign at Schools- 1 and -3 , and since less than three samples was deemed unacceptable, these were omitted from the data analysis. The different appearance of the VOC profiles of the classrooms and the kindergartens lead to the notion that there were different indoor sources in the two microenvironments. Table 1 also presents the mean toluene/benzene and toluene/ TVOC $_{51}$ ratios, and $\mathrm{TVOC}_{51}$ concentrations for kindergartens. In general, the TVOC $_{51}$ concentrations and toluene/TVOC 51 ratios were higher for kindergartens than classrooms ( $p=0.046$ and 0.028 , respectively), whereas toluene/benzene ratios were higher in the kindergartens for four of the seven sampling campaigns; however, the difference was not significant. In addition, the mean number of VOCs detected in all of the samples was higher in the kindergartens (20) than the classrooms (17). Consequently, differences in dominant VOC profiles, TVOC $_{51}$ concentrations, toluene/benzene and toluene/TVOC 51 ratios, and number of detected VOCs between the kindergartens and the classrooms point to existence of different sources in the two microenvironments. Actually, 1,4-dichlorobenzene (a compound frequently detected in the classrooms) was not detected in any of the kindergarten samples. A source characterization study (Guo et al., 2003) for BTEX compounds identified two source factors in schools: one characterized by high contribution of benzene, toluene, ethylbenzene, and $p, m$-xylene, and the other by $o$-xylene. In this study, $o$-xylene was among the relatively highconcentration VOCs in kindergartens but not in classrooms. The difference between the kindergartens and the classrooms (i.e., in flooring materials (carpet or polymeric material vs. ceramic or stone hard flooring, respectively), the variety of materials for various activities for children, having a kitchen for lunch and snacks, and cleaning practices), results in a different indoor air quality in terms of VOCs.

The mean TVOC $_{51}$ concentrations measured in this study ranged from 33 to $130 \mu \mathrm{g} / \mathrm{m}^{3}$. In a review of the literature, Daisey et al. (2003) reported high indoor TVOC concentrations in Italian nurseries and kindergartens (a median of $3600 \mu \mathrm{g} / \mathrm{m}^{3}$ ) which were higher than secondary schools (a median of $2600 \mu \mathrm{g} / \mathrm{m}^{3}$ ), whereas the mean TVOC concentration was reported as $90 \mu \mathrm{g} / \mathrm{m}^{3}$ from a Swedish study for kindergartens. Kotzias (2005) reported that the VOC concentrations measured in kindergartens varied from 25 to $53 \mu \mathrm{g} / \mathrm{m}^{3}$ in Catania, Italy, and from 19 to $36 \mu \mathrm{g} / \mathrm{m}^{3}$ in Arnhem and Nijmegen, the Netherlands. The TVOC concentrations measured by Yang et al. (2009) in South Korea kindergartens had a mean value of $642 \mu \mathrm{g} / \mathrm{m}^{3}$ (range: $264-1024 \mu \mathrm{g} / \mathrm{m}^{3}$ ). The TVOC $_{51}$ concentrations measured in this study are in the range of those measured in Southern and Central European cities (Kotzias, 2005), lower (about 6-fold) than those measured in Korea (Yang et al., 2009), and much lower (up to 80 -folds) than those reported in the review article by Daisey et al. (2003).

Kindergarten formaldehyde levels measured in this study were higher than the highest VOC (toluene) concentrations (Fig. 2). Actually, the formaldehyde levels were comparable to TVOC $_{51}$ concentrations ( $p=0.24$, Table 1$)$. Kindergarten formaldehyde levels were higher than those measured in classrooms $(p=0.018)$. Unlike TVOC concentrations, the difference in urban and suburban formaldehyde concentrations was not significant $(p=0.44)$. Comparison could be performed to the concentrations measured in fall and spring campaigns (because winter data were missing for two schools); although the difference between the median values were large $\left(89 \mu \mathrm{g} / \mathrm{m}^{3}\right.$ vs. $\left.76 \mu \mathrm{g} / \mathrm{m}^{3}\right)$, it was not statistically significant $(p=0.11)$. So, it can be asserted that there were consistent sources of formaldehyde in the kindergartens because neither seasonal nor spatial differences were significant.

According to the review by Daisey et al. (2003), the average formaldehyde concentration measured in 10 Danish daycare cen- ters was approximately $100 \mu \mathrm{g} / \mathrm{m}^{3}$ (from a study published in 1982). The concentration range was reported as $6-11 \mu \mathrm{g} / \mathrm{m}^{3}$ for Dutch kindergartens (Kotzias, 2005). Formaldehyde concentrations measured in Korean kindergartens (Yang et al., 2009) were higher with a mean value of $195 \mu \mathrm{g} / \mathrm{m}^{3}$ (range: $45-690 \mu \mathrm{g} / \mathrm{m}^{3}$ ). The overall average of the concentrations measured in this study $\left(85 \mu \mathrm{g} / \mathrm{m}^{3}\right)$ was clearly higher than the Dutch, and in the range of the Danish and Korean kindergartens.

\section{Playground}

Samples were collected from outdoor playgrounds in the campus of each school. Similar to kindergartens, because the number of samples collected in each campaign was low $(n=3)$, evaluations presented in this section are based on the compounds that were detected in all three samples. The number of compounds that comply with this criterion ranged from 18 (School-3, spring) to 26 (School-1, winter); overall average was 21 compounds, which is similar to the kindergartens but higher than the classrooms. The difference in the median number of VOCs detected in all samples between indoors (classroom and kindergarten pooled) and outdoors is statistically significant $(p=0.01)$. Toluene and benzene were the abundant compounds in all campaigns, unlike indoors; however, benzene had higher mean concentrations than toluene in two campaigns for outdoors (Fig. 3). In addition, neither of the two compounds reached the two-digit concentrations in the five campaigns, and at least one was at one-digit level in two of the four remaining campaigns. The other frequently detected high-concentration $\left(\geq 1 \mu \mathrm{g} / \mathrm{m}^{3}\right)$ compounds were 1,3-dichlorobenzene, $p, m$-xylene, and naphthalene. The number of abundant species and their concentrations were lower outdoors compared to indoor air. Table 1 also presents the mean toluene/benzene and toluene/TVOC 51 ratio values, and $\mathrm{TVOC}_{51}$ concentrations for playgrounds. The median outdoor $\mathrm{TVOC}_{51}$ level was lower than the indoor level $(p<0.001)$. The difference in indoor and outdoor toluene/benzene ratios was significant $(p=0.01)$ whereas the difference in the toluene/TVOC ${ }_{51}$ ratio was not $(p=0.42)$. Consequently, differences in dominant VOC profiles, TVOC $_{51}$ concentrations, toluene/benzene ratios, and number of detected VOCs between the indoors and the outdoor playgrounds point to the existence of different sources indoors, while it may still be influenced by the outdoor sources. Indoor/outdoor (I/O) ratios were calculated for the most abundant nine VOCs and TVOC $_{51}$ (Fig. 4, 10th to 90th percentile bars were not calculated for 1,3-dichlorobenzene and styrene because sample sizes were insufficient as these were not detected in all the samples either in indoor or outdoors). Kindergarten I/O values show that the indoor sources were stronger compared to classrooms or the classrooms were better ventilated. While there were occurrences of $\mathrm{I} / \mathrm{O}<1$ for only benzene for kindergartens, only naphthalene had no occurrence of $\mathrm{I} / \mathrm{O}<1$ in the 10th to 90th percentile range for classrooms. The mean I/O values of TVOC $_{51}$ were 2.1 for the classrooms and 3.5 for the kindergartens, which show that there were strong indoor sources for the both microenvironments. The mean $\mathrm{I} / \mathrm{O}$ values for all the compounds presented in Fig. 4 were $>1$ (six VOCs with 1.3-1.8, and three VOCs with $>2$ : toluene 2.1 , naphthalene 4.9, and 1,3-dichlorobenzene 5.1) for the classrooms, whereas all the mean $\mathrm{I} / \mathrm{O}$ values were $>2$ for kindergartens (from 2.2 for benzene to 5.5 for 1,2,4-trimethylbenzene) except for styrene (1.9). The difference in the median $\mathrm{I} / \mathrm{O}$ values for the classrooms and the kindergartens were significant for only toluene $(p=0.005)$ and TVOC $_{51}(p=0.05)$.

The difference in the median $\mathrm{I} / \mathrm{O}$ values between the classrooms and the kindergartens was also significant for formaldehyde $(p=0.005)$. The mean $\mathrm{I} / \mathrm{O}$ values were $>10$ for both of the microenvironments, therefore, formaldehyde had the strongest indoor 

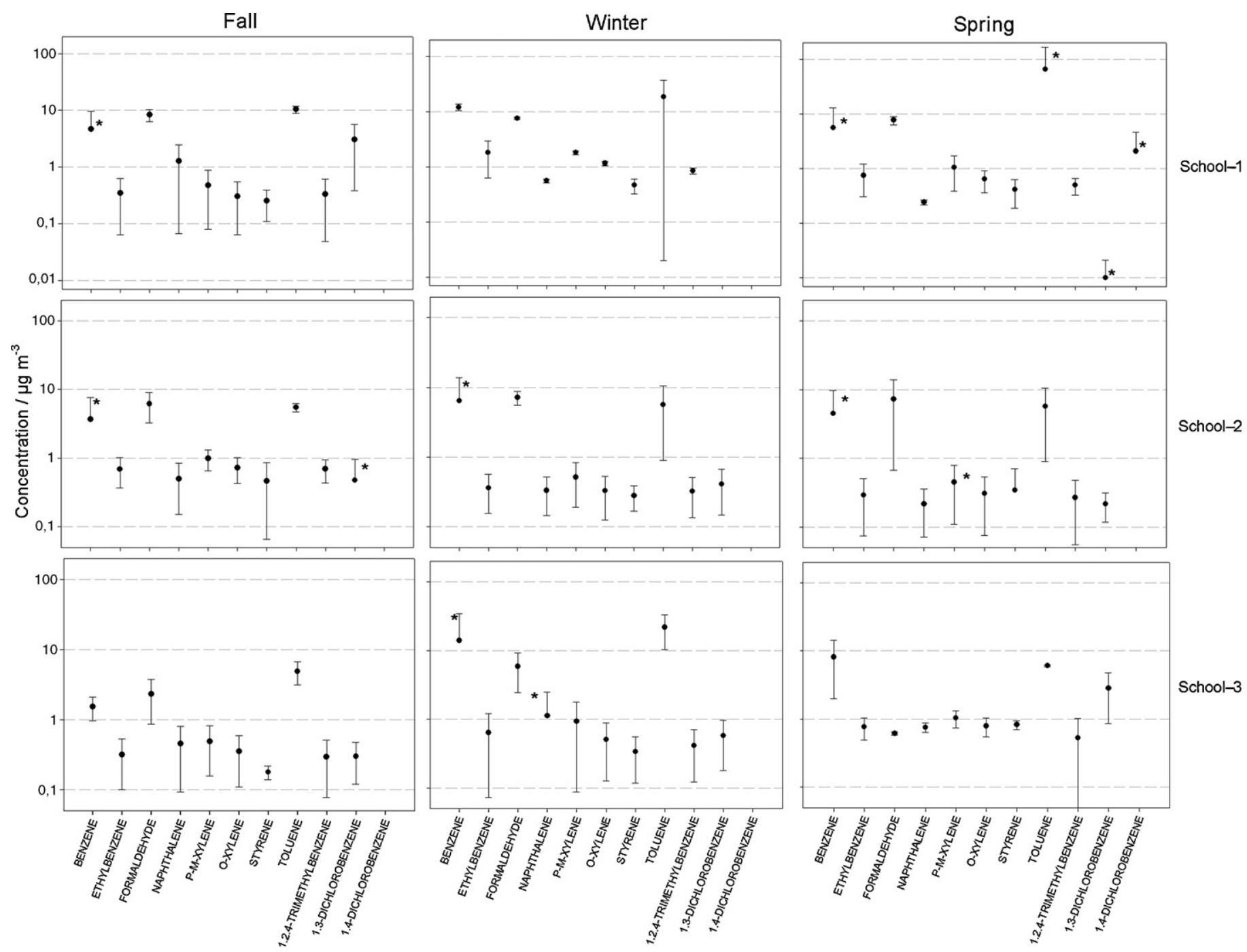

School-2
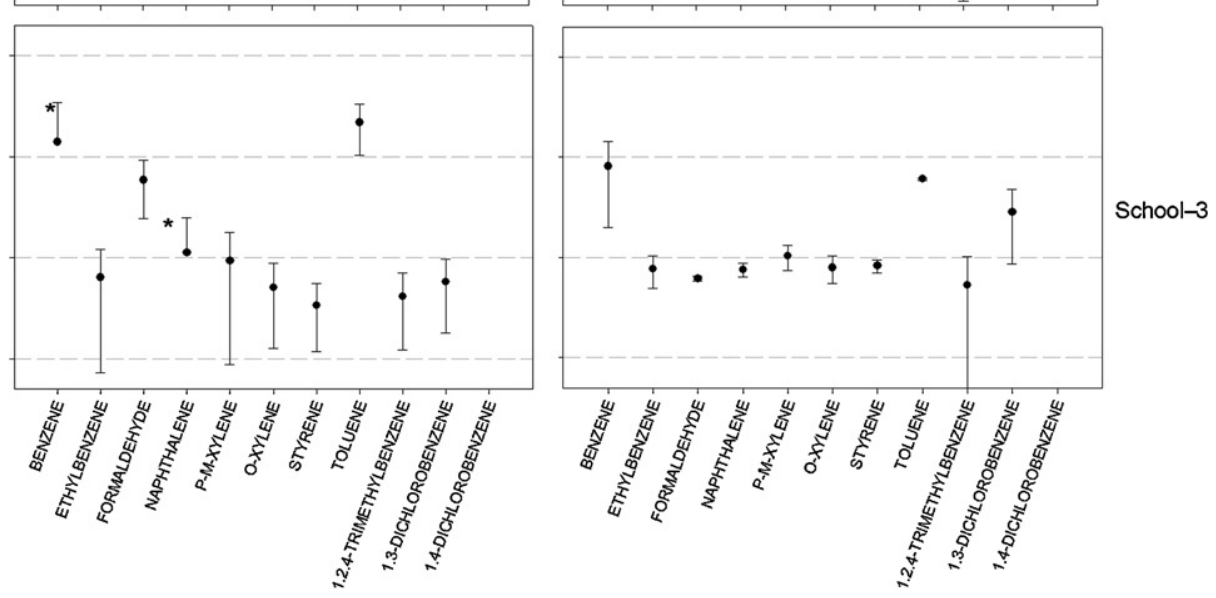

*Lower standard deviation bars do not show because they exceed the range

Fig. 3. Season-school matrix for outdoor VOC concentrations measured on the outdoor playgrounds.

sources compared to the VOCs. Playground outdoor formaldehyde concentrations were at least an order of magnitude lower compared to the indoor concentrations (see Table 1). The difference between the indoor and the outdoor concentrations was significant $(p<0.001)$. The indoor formaldehyde levels were comparable to
TVOC $_{51}$ levels, however formaldehyde concentrations were lower than the TVOC $_{51}$ concentrations $(p<0.001)$. The seasonal outdoor playground concentration differences were not significant, whereas urban and suburban median concentrations differed significantly $(p=0.002)$.
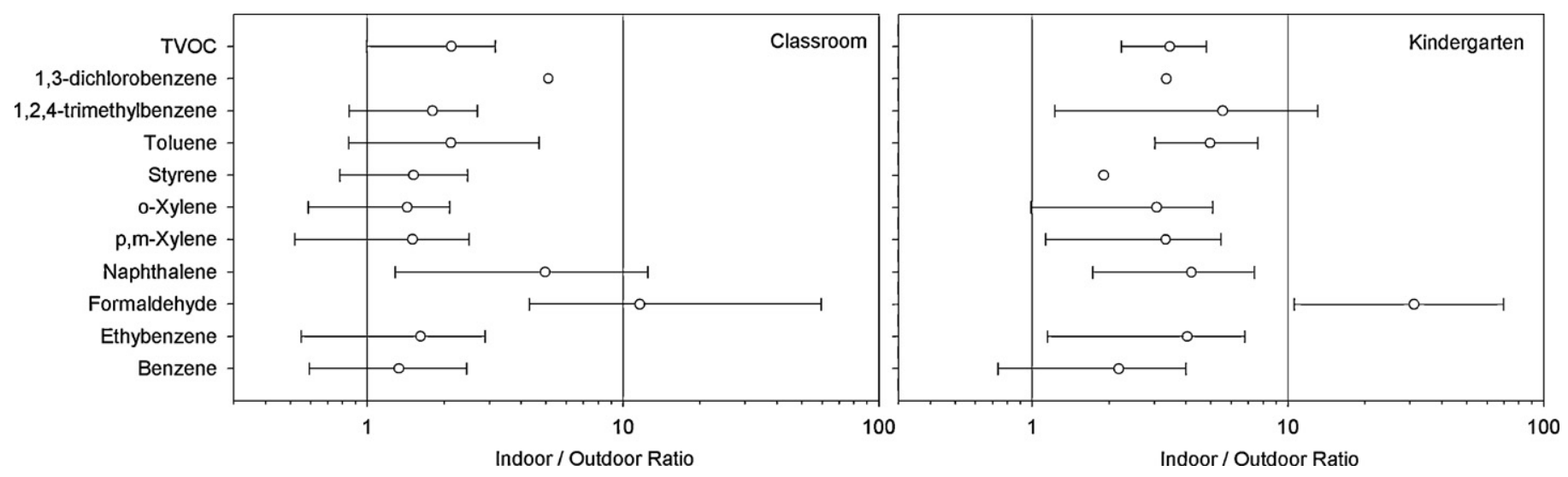

Fig. 4. The mean indoor/outdoor ratios (bars represent10th to 90th percentile range). 
Table 2

Odor, sensory irritation, and chronic toxicity quotient levels.

\begin{tabular}{|c|c|c|c|c|c|c|c|c|c|}
\hline & \multirow[t]{2}{*}{ OT } & \multirow[t]{2}{*}{$\operatorname{SIT}(\mathrm{ppb})$} & \multirow[t]{2}{*}{ CTT } & \multicolumn{3}{|c|}{ Classroom } & \multicolumn{3}{|c|}{ Kindergarten } \\
\hline & & & & OQ & SIQ & CTQ & OQ & SIQ & CTQ \\
\hline Formaldehyde & 870 & 77 & 2.4 & 0.077 & 0.87 & 28 & 0.12 & 1.3 & 43 \\
\hline Benzene & - & - & 19 & & & 0.044 & & & 0.47 \\
\hline Naphthalene & 15 & - & 1.7 & 0.069 & & 0.61 & 0.037 & & 0.33 \\
\hline Toluene & - & - & 80 & & & 0.27 & & & 0.30 \\
\hline Carbontetrachloride & - & - & 6.4 & & & 0.022 & & & 0.039 \\
\hline Tetrachloroethene & - & - & 5.2 & & & 0.032 & & & 0.021 \\
\hline Xylenes (total) & - & - & 160 & & & 0.010 & & & 0.019 \\
\hline 1,2,4-Trimethylbenzene & 160 & - & 120 & 0.002 & & 0.003 & 0.013 & & 0.017 \\
\hline Bromoform & - & - & 1.3 & & & 0.009 & & & 0.008 \\
\hline Trichloroethene & - & - & 110 & & & 0.006 & & & 0.006 \\
\hline $1,3,5$-Trimethylbenzene & 230 & - & 120 & 0.000 & & 0.001 & 0.003 & & 0.005 \\
\hline Chloroform & - & - & 61 & & & 0.011 & & & 0.003 \\
\hline Ethylbenzene & - & - & 460 & & & 0.001 & & & 0.003 \\
\hline Isopropylbenzene & 100 & - & 81 & 0.000 & & 0.000 & 0.002 & & 0.003 \\
\hline Styrene & 140 & - & 210 & 0.002 & & 0.001 & 0.002 & & 0.001 \\
\hline Chlorobenzene & - & - & 220 & & & 0.000 & & & 0.000 \\
\hline 1,1,1-Trichloroethane & - & - & 180 & & & 0.000 & & & 0.000 \\
\hline$p, m$-Xylene & 320 & - & - & 0.002 & & & 0.004 & & \\
\hline$o$-Xylene & 850 & - & - & 0.000 & & & 0.001 & & \\
\hline N-Propylbenzene & 320 & - & - & 0.000 & & & 0.001 & & \\
\hline
\end{tabular}

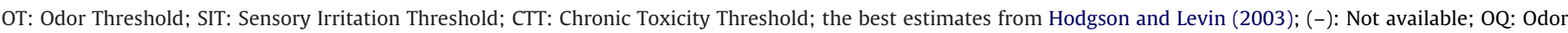
Quotient; SIQ: Sensory Irritation Quotient; CTQ: Chronic Toxicity Quotient.

\section{Health-risk assessment}

Although unpleasant odors caused by VOCs may not have serious health effects, they may play a major role in the perception of indoor air quality in a building. The second way that some of the VOCs involve in sensory perception occurs through irritation of the eyes and upper respiratory tract. In addition to the sensory effects, even at the low indoor air levels VOCs may be associated with chronic toxic (non-cancer) and carcinogenic health effects. Hazard Quotients (Odor Quotient, OQ, Sensory Irritation Quotient, SIQ and Chronic Toxicity Quotient, CTQ defined by Hodgson and Levin [2003]) were calculated to classify measured indoor VOCs into three categories ( $\mathrm{HQ}>1,0.1<\mathrm{HQ} \leq 1$, and $\mathrm{HQ} \leq 0.1)$. The calculated $\mathrm{OQ}$, SIQ and CTQ levels using the 95th percentile indoor concentrations measured in this study and the threshold values from Hodgson and Levin (2003) are presented in Table 2. The quotient values that fall into the first $(>1.0)$ and the second $(0.1-1.0)$ categories are pre- sented; indicated with bold italics and italics, respectively. All OQ values were $<0.1$ except for formaldehyde in the kindergartens (the second category). Since a threshold value was available for only formaldehyde among the measured compounds in this study, no categorization could be made for sensory irritation. SIQ value for formaldehyde fell into the second and the first categories for the classrooms and the kindergartens, respectively. Formaldehyde was also in the first category for chronic toxic effects with very high values for both classrooms and kindergartens. Naphthalene and toluene were in the second category for both classrooms and kindergartens whereas benzene was in the second category for the kindergartens.

For the pollutants with published risk factors in the IRIS database, health-risk assessment (RA) was conducted using MonteCarlo simulation. RA for chronic toxic effects (noncarcinogenic) was conducted for benzene, ethylbenzene, isopropylbenzene (cumene), naphthalene, styrene, toluene, 1,1,1-trichloroethane, and xylenes
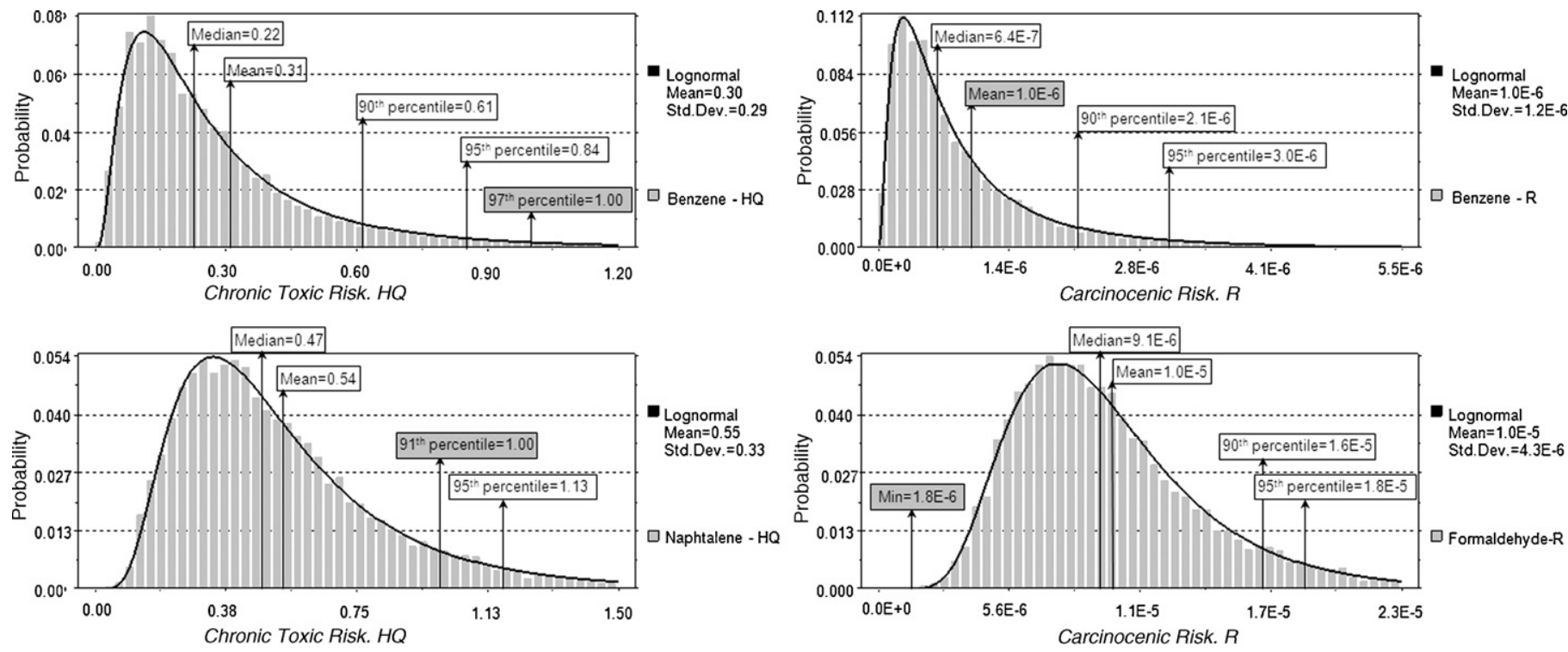

Fig. 5. Statistics, frequency and fitted distributions of chronic toxic risk: (a) benzene, (b) naphthalene, and carcinogenic risk (c) benzene, (d) formaldehyde. 
(total). Carcinogenic RA was conducted for benzene, bromoform, carbontetrachloride, chloroform, and formaldehyde. The noncarcinogenic risk levels were less than the threshold $(\mathrm{HQ}=1)$ for ethylbenzene, cumene, styrene, toluene, 1,1,1-trichloroethane, and xylenes even at the 95th percentile level; therefore, results are presented for only benzene and naphthalene (see Fig. 5a and b). The carcinogenic risk levels were below the acceptable risk level of one in a million for bromoform, carbon tetrachloride, and chloroform even at the 95th percentile level; therefore, results are presented for only benzene and formaldehyde (see Fig. $5 c$ and d). Distributional statistics that mark the risk demarcation levels are denoted with gray colored stat boxes in the figures. As seen in Fig. 5a and $\mathrm{b}$, the noncarcinogenic risk levels are not considerably high as only $3 \%$ and $9 \%$ of the HQ values are greater than the threshold level for benzene and naphthalene, respectively. We may conclude that the noncarcinogenic risk levels due to the school life through kindergarten to 8th grade is not significant since only a small percentage of the population $(2 \%)$ had considerable risk $\left(\mathrm{HQ}_{\text {benzene }}>1.2\right.$ and $\mathrm{HQ}_{\text {naphthalene }}>1.5$ ). However, one should note that the risk was calculated for the specified time period ( $5 \mathrm{~h}$ that is $4 \mathrm{~h}$ indoors and $1 \mathrm{~h}$ outdoors a day at school, for nine years), and when the chronic daily intake that occurs at home is taken into account, these risk levels will increase. Home exposure could not be accounted in this study as it was outside its scope. The carcinogenic risk levels are not as low as the chronic toxic risks for two compounds. The mean population risk for benzene $\left(1.0 \times 10^{-6}\right)$ corresponds to the 69 th percentile. In other words, about $30 \%$ of the population risk levels are greater than the acceptable risk level. Ten percent of the population risk are twotimes, and $5 \%$ of the population risk are three-times the acceptable carcinogenic risk due to benzene in air. The situation is more serious for formaldehyde as even the minimum risk value out of the simulation is about two-times the acceptable risk level. Approximately half of the population has a carcinogenic risk $>1.0 \times 10^{-5}$ associated with the formaldehyde in air during the kindergarten plus primary school years. The above carcinogenic risk levels are low compared to the upper-bound cancer risk levels estimated for New York City and Los Angeles, USA, teenagers (Sax et al., 2006). New York City and Los Angeles median and mean risk levels were $2.2 \times 10^{-4}$ and $2.7 \times 10^{-4}$ for formaldehyde and $2.5 \times 10^{-5}$ and $3.2 \times 10^{-5}$ for benzene, respectively. However, it should be noted that these levels were based on the personal exposures that represented the whole $24 \mathrm{~h}$.

\section{Conclusions}

Higher VOC concentrations were measured indoors than outdoors. Seasonal and spatial variations of the most abundant species were not significant, pointing at dominant indoor sources, whereas the effect of outdoor sources cannot be disregarded. Pollutant profiles differed between the kindergartens and the classrooms, and concentrations measured in the kindergartens were higher. Benzene, toluene, and formaldehyde were the most abundant compounds. Naphthalene and dichlorobenzene were the other notable compounds for which moth balls and cleaning products might be important sources. Formaldehyde was classified as the primal concern among the VOCs measured in this study followed by benzene, naphthalene, and toluene as the secondary category. Formaldehyde and benzene were also of concern as the associated carcinogenic risk estimates were above the acceptable level of $1.0 \times 10^{-6}$.

Although the number of schools in which the samples were taken is limited, seasonal variations in VOC concentrations, including formaldehyde, have been reported for primary school classrooms, kindergartens, and outdoor playgrounds for the first time in Turkey. Additionally, health-risk assessment was conducted for odor detection, sensory irritation, chronic toxic effects, and cancer.

\section{Acknowledgments}

This study was supported by a research grant (105Y263) from the Scientific and Technical Research Council of Turkey (TUBITAK). GC-MS and HPLC analyses were performed at Environmental Research Center, İzmir Institute of Technology. We thank Dr. M. Odabasi for his help during method development for TD-GC-MS analysis.

\section{Appendix A. Supplementary data}

Supplementary data associated with this article can be found, in the online version, at doi:10.1016/j.ijheh.2010.08.008.

\section{References}

Adgate, J.L., Church, T.R., Ryan, A.D., Ramachandran, G., Fredrickson, A.L., Stock, T.H., Morandi, M.T., Sexton, K., 2004. Outdoor, indoor, and personal exposure to VOCs in children. Environ. Health Perspect. 112, 1386-1392.

ALA (American Lung Association), 2007. Diseases - Asthma \& Children Fact Sheet., http://www.lungusa.com.

Bayer, C.W., Crow, S.A., Fischer, J., 2000. Causes of Indoor Air Quality Problems in Schools: Summary of Scientific Research, A Report to Department of Energy. Energy Division, Oak Ridge National Laboratory, Oak Ridge, TN.

Daisey, J.M., Angell, W.J., Apte, M.G., 2003. Indoor air quality, ventilation and health symptoms in schools: an analysis of existing information. Indoor Air 13, 53-64.

Demir, A.U., Karakaya, G., Bozkurt, B., Şekerel, B.E., Kalyoncu, A.F., 2004. Asthma and allergic diseases in schoolchildren: third cross-sectional survey in the same primary school in Ankara, Turkey. Pediatr. Allergy Immunol. 15, 531-538.

Faustman, E.M., Silbernagel, S.M., Fenske, R.A., Burbacher, T.M., Ponce, R.A., 2000. Mechanisms underlying children's susceptibility to environmental toxicants. Environ. Health Perspect. 108 (S1), 13-21.

Gelencsér, A., Siszler, K., Hlavay, J., 1997. Toluene-Benzene concentration ratio as a tool for characterizing the distance from Vehicular Emission Sources. Environ. Sci. Technol. 31, 2869-2872.

Godwin, C., Batterman, S., 2007. Indoor air quality in Michigan schools. Indoor Air $17,109-121$.

Guo, H., Lee, S.C., Lia, W.M., Cao, J.J., 2003. Source characterization of BTEX in indoor microenvironments in Hong Kong. Atmos. Environ. 37, 73-82.

Hanoune, B., LeBris, T., Allou, L., Marchand, C., Calve, L.S., 2006. Formaldehyde measurements in libraries: comparison between Infrared Diode Laser Spectroscopy and a DNPH-derivatization method. Atmos. Environ. 40, 5768-5775.

Hodgson, A.T., Levin, H., 2003. Classification of Measured Indoor Volatile Organic Compounds based on Noncencer Health and Comfort Considerations. Lawrence Berkley National Laboratory (LBNL-53308), Berkley, CA.

IRIS (Integrated Risk Information System of U.S. Environmental Protection Agency), 2009. http://www.epa.gov/iris.

Kavcar, P., Odabasi, M., Kitis, M., Inal, F., Sofuoglu, S.C., 2006. Occurrence, oral exposure and risk assessment of VOCs in drinking water for İzmir. Water Res. 40, 3219-3230.

Khoder, M.I., 2006. Formaldehyde and aromatic volatile organic hydrocarbons in the indoor air of Egyptian office buildings. Indoor Built Environ. 15, 379-387.

Kotzias, D., 2005. Indoor air and human exposure assessment - needs and approaches. Exp. Toxicol. Pathol. 57, 5-7.

Kurt, E., Metintas, S., Basyigit, I., et al., 2007. Prevalence and risk factors of allergies in Turkey: results of a multicentric cross-sectional study in children. Pediatr. Allergy Immunol. 18, 566-574

Lee, S.C., Guo, H., Li, W.M., Chan, L.Y., 2002. Inter-Comparison of air pollutant concentrations in different indoor environments in Hong Kong. Atmos. Environ. 36, 1929-1940.

Mendell, M.J., Heath, G.A., 2005. Do indoor pollutants and thermal conditions in schools influence student performance? A critical review of the literature. Indoor Air 15, 27-52.

Mendell, M.J., 2007. Indoor residential chemical emissions as risk factors for respiratory and allergic effects in children: a review. Indoor Air 17, 259-277.

Mentese, S., Gullu, G., 2006. Variations and sources of formaldehyde levels in residential indoor air in Ankara, Turkey. Indoor Built Environ. 15, 273-281.

Muezzinoglu, A., Odabasi, M., Onat, L., 2001. Volatile organic compounds in the air of Izmir, Turkey. Atmos. Environ. 35, 753-760.

Neyzi, O., Yalcindag, A., Alp, H., 1973. Heights and weights of Turkish children. J. Trop. Pediatr. 19, 5-13.

Neyzi, O., Günoz, H., Furman, A., Bundak, R., Gokçay, G., Darendeliler, F., Baş, F., 2008. Türk çocuklarında vücut ağırlığı, boy uzunluğu, baş çevresi ve vücut kitle indeksi referans değerleri. Cocuk Sağlığı ve Hastalıkları Dergisi 51,1-14 (in Turkish).

Norback, D., Torgen, M., Edling, C., 1990. Volatile organic compounds, respirable dust, and personal factors related to prevalence and incidence of sick building syndrome in primary schools. Br. J. Ind. Med. 47, 733-741.

Ones, U., Sapan, N., Yazicioglu, M., Guler, N., Tamay, Z., Somer, A., Canitez, Y., 2005. The first camps in Turkey for asthmatic children: six years' experience. Turk. J. Pediatr. 47, 222-226. 
Park, J.S., Ikeda, K., 2006. Variations of formaldehyde and VOC levels during three years in new and older homes. Indoor Air 16, 129-135.

Pekey, H., Arslanbaş, D., 2008. The relationship between indoor, outdoor and personal VOC concentrations in homes, offices and schools in the metropolitan region of Kocaeli, Turkey. Water Air Soil Pollut. 191, 113-129.

Righi, E., Aggazzotti, G., Fantuzzi, G., Ciccarese, V., Predieri, G., 2002. Air quality and well-being perception in subjects attending university libraries in Modena (Italy). Sci. Total Environ. 286, 41-50.

Rumchev, K., Spickett, J., Bulsara, M., Phillips, M., Stick, S., 2004. Association of domestic exposure to volatile organic compounds with asthma in young children. Thorax 59, 746-751.

Sax, S.N., Bennett, D.H., Chillrud, S.N., Ross, J., Kinney, P.L., Spengler, J.D., 2006. A cancer risk assessment of inner-city teenagers living in New York City and Los Angeles. Environ. Health Perspect. 114, 1558-1566.

Selcuk, Z.T., Caglar, T., Enunlu, T., Topal, T., 1997. The prevalence of allergic diseases in primary school children in Edirne, Turkey. Clin. Exp. Allergy 27, 262-269.

Sexton, K., Mongin, S.J., Adgate, J.L., Pratt, G.C., Ramachandran, G., Stock, T.H. Morandi, M.T., 2007. Estimating volatile organic compound concentrations in selected microenvironments using time-activity and personal exposure data. J. Toxicol. Environ. Health A 70, 465-476.

Shendell, D.G., Winer, A.M., Stock, T.H., Zhang, L., Zhang, J., Maberti, S., Colome, S.D. 2004. Air concentrations of VOCs in portable and traditional classrooms: results of a pilot study in Los Angeles County. J. Expo. Anal. Environ. Epidemiol. 14, 44-59.
Smedje, G., Norback, D., Edling, C., 1997. Subjective indoor air quality in schools in relation to exposure. Indoor Air 7, 143-150.

Stellman, J.M., 1998. Encyclopaedia of Occupational Health and Safety, vol. II. International Labour Office, Geneva, p. 44.8.

USEPA (United States Environmental Protection Agency), 1997a. Exposure Factors Handbook. Office of Research and Development, National Center for Environmental Assessment, EPA/600/P-95/002Fa, Washington, DC.

USEPA, 1997b. Guiding Principles for Monte Carlo Analysis. Risk Assessment Forum. EPA/630/R-97/001, Washington, DC.

USEPA, 1999a. Compedium Method TO-17, Determination of Volatile Organic Compounds in Ambient Air Using Active Sampling onto Sorbent Tubes, 2nd ed. Environmental Protection Agency Cincinnati, OH.

USEPA, 1999b. Compedium Method TO-11, Determination of Formaldehyde in Ambient Air Using Adsorbent Cartridge Followed by High Performance Liquid Chromatography (HPLC). Environmental Protection Agency Cincinnati, $\mathrm{OH}$.

Vaizoglu, S.A., Aycan, S., Deveci, M.A., et al., 2003. Determining domestic formaldehyde levels in Ankara, Turkey. Indoor Built Environ. 12, 329-335.

Yang, W., Sohn, J., Kim, J., Son, B., Park, J., 2009. Indoor air quality investigation according to age of the school buildings in Korea. J. Environ. Manage. 90, 348-354.

Zhang, G., Spickett, J., Rumchev, K., Lee, A.H., Stick, S., 2006. Indoor environmental quality in a 'low allergen' school and three standard primary schools in Western Australia. Indoor Air 16, 74-80. 